
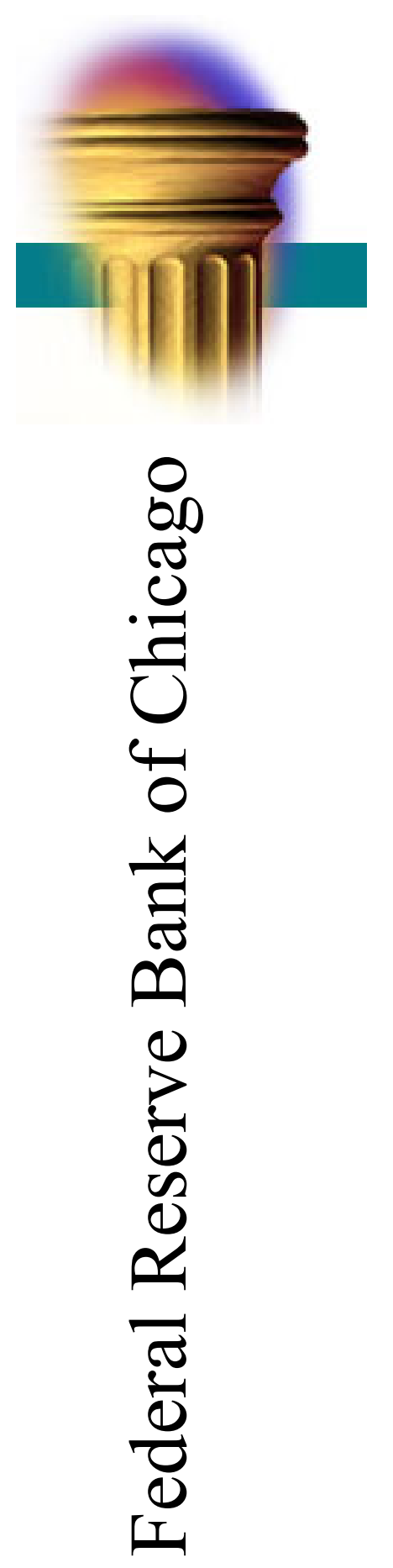

\title{
A Sequential Bargaining Model of the Fed Funds Market with Excess Reserves
}

Sam Schulhofer-Wohl and James Clouse

\section{REVISED \\ July 2018}

\section{WP 2018-08}

\section{https://doi.org/10.21033/wp-2018-08}

${ }^{*}$ Working papers are not edited, and all opinions and errors are the responsibility of the author(s). The views expressed do not necessarily reflect the views of the Federal Reserve Bank of Chicago or the Federal Reserve System. 


\title{
A Sequential Bargaining Model of the Fed Funds Market with Excess Reserves*
}

\author{
Sam Schulhofer-Wohl and James Clouse
}

Revised July 2018

\begin{abstract}
We model bargaining between non-bank investors and heterogeneous bank borrowers in the federal funds market. The analysis highlights how the federal funds rate will respond to movements in other money market interest rates in an environment with elevated levels of excess reserves. The model predicts that the administered rate offered through the Federal Reserve's overnight reverse repurchase agreement facility influences the fed funds rate even when the facility is not used. Changes in repo rates pass through to the federal funds rate, but by less than one-for-one. We calibrate the model to data from 2017 and find in an out-of-sample test that the model quantitatively matches the increase in the federal funds rate in the first four months of 2018. The rise in the fed funds rate in 2018 is attributed to movements in repo rates and not to changes in the scarcity value of reserves.
\end{abstract}

* Schulhofer-Wohl: Federal Reserve Bank of Chicago. Clouse: Board of Governors of the Federal Reserve System. The views expressed herein are those of the authors and not necessarily those of the Board of Governors or the staff of the Federal Reserve System or the Federal Reserve Bank of Chicago. 


\section{Introduction}

The Federal Open Market Committee adjusts the stance of monetary policy primarily by changing its target range for the effective federal funds rate (EFFR). The EFFR is a market rate on overnight transactions between banks and other institutions that are eligible to participate in the federal funds market. The aggregate supply of reserves in the banking system is currently about $\$ 2$ trillion (Board of Governors of the Federal Reserve System, 2018), far in excess of what most observers believe to be the quantity that banks need to hold to meet reserve requirements and liquidity needs. Trading in the fed funds market at present is therefore largely motivated by institutions' desire to arbitrage differences between the interest rate that the Fed pays on excess reserves held by depository institutions and other, lower money market rates (Ihrig, Meade, and Weinbach, 2015).

Figure 1 shows the EFFR, the interest rate on excess reserves (IOER), and two other important interest rates in the period since the FOMC began increasing interest rates on December 17, 2015. The EFFR has typically been stable at a point partway between IOER and the interest rate at the Fed's overnight reverse repurchase agreement (ON RRP) facility, except that the EFFR spikes downward at the end of most months. Meanwhile, until 2018, market repo rates - measured in the figure by the Federal Reserve Bank of New York's Broad General Collateral Rate (BGCR) index - typically remained close to the ON RRP rate. More recently, market repo rates have risen significantly above the ON RRP rate, the fed funds rate has moved up toward IOER, and the month-end and quarter-end spikes have become smaller.

In this paper, we build a simple model of how the level of the EFFR is affected by changes in the Federal Reserve's policy tools, bank balance sheet costs, and other market interest rates, in an environment with abundant reserves. The model explains the key dynamics shown in Figure 1, including the position of EFFR between IOER and ON RRP, the month-end spikes, and the changes in these magnitudes in 2018. We calibrate the model to a subset of the data, validate it out of sample, and use it to assess the causes of recent rate dynamics as well as the consequences of a reduction in deposit insurance premiums that is scheduled to take place no later than the end of 2018.

The core of the model is a bargaining problem between lenders and borrowers in the 


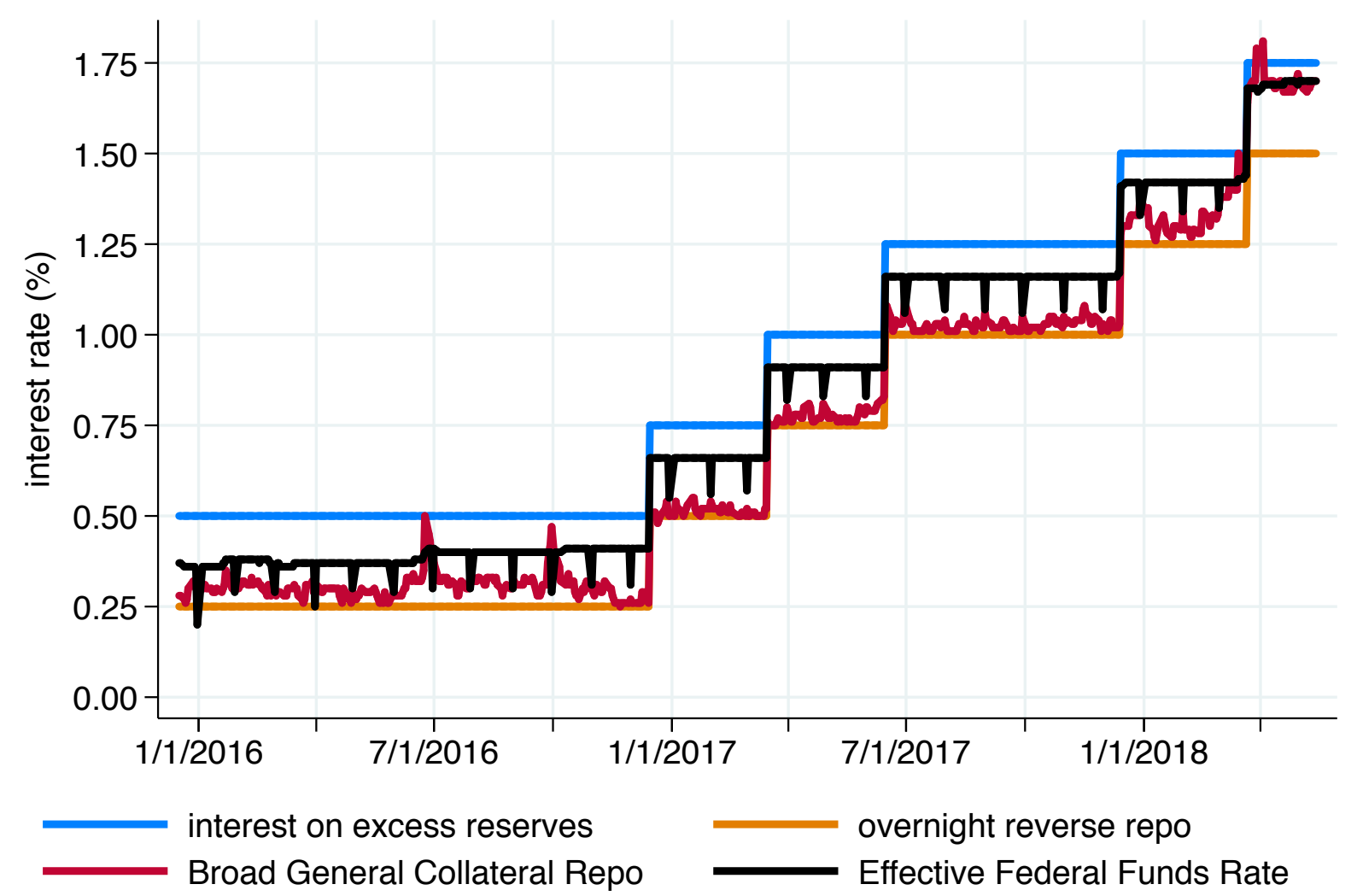

Figure 1: Money market interest rates since the start of policy normalization. Source: Federal Reserve Bank of New York. BGCR data before April 2, 2018, are indicative historical values.

fed funds market, similar to Bech and Klee (2011). Because both depository institutions and government-sponsored enterprises (GSEs) can hold reserves but only depository institutions can earn interest on reserves, there are gains from trade whenever a GSE lends to a depository institution, which the borrower and lender must divide in some manner. We assume that the parties split the gains from trade according to generalized Nash (1950) bargaining: Each party receives a share of the surplus proportional to its bargaining power. We extend the literature by modeling in more detail the gains from trade and the outside options of the players. First, whereas Bech and Klee (2011) assumed arbitrage was costless for banks, we allow for banks to have costs of expanding their balance sheets to borrow fed funds and for that cost to vary between domestic and foreign banks; this aspect of the model allows us to assess how a change in deposit insurance premiums would move the fed funds rate. Second, we explicitly model how the ON RRP rate and repo rates affect GSEs' outside option and 
hence the gains from trade; this allows us to examine the relationship between the rise in repo rates and the rise in the fed funds rate in 2018. Third, in our model, the outside option when a GSE is bargaining with one bank includes the possibility of bargaining with a different bank; this feature allows us to explain how the rate can be influenced by institutions that are not parties to the transaction.

Our model views the fed funds market as involving a small number of well-informed borrowers and lenders. We abstract from search frictions or imperfect information about counterparties' costs and returns - frictions that play a key role in the search-based models of Armenter and Lester (2017) and Afonso, Armenter, and Lester (2018) — so that we can highlight the way that the fed funds rate is determined by how institutions split a time-varying surplus. We view this abstraction as reasonable given that the fed funds market is populated by a relatively small number of institutions that trade with each other repeatedly and can easily become well informed about the regulations and interest rates that drive marginal costs and benefits of borrowing and lending. Similarly, we abstract from most heterogeneity between banks in order to highlight one particularly impactful form of heterogeneity: the different regulations facing domestic and foreign banks in the U.S. market. These simplifications mean that our model can explain the central tendency of rates in the federal funds market - the official EFFR is a volume-weighted median of rates on different transactions — but not the heterogeneity in transacted rates.

In addition, the model assumes an environment with high levels of excess reserves and therefore, unlike Afonso, Armenter, and Lester (2018), has little to say about the comparative statics of changes in the supply of reserves. However, we do allow for reserves to have some scarcity value and let the data tell us whether this value has changed since the Fed began to shrink the supply of reserves in late 2017.

We have four key findings. First, we find that institutions and facilities that are not active in the market can nonetheless significantly influence the fed funds rate. For example, in the model, the ON RRP facility is not used, consistent with the very low observed volumes in this facility, but its rate nonetheless affects the fed funds rate. Similarly, domestic banks' balance sheet costs affect the fed funds rate even though they are not the main borrowers in the market away from quarter-end. Second, the model predicts that exogenous changes in 
repo rates pass through to the fed funds rate but by less than one-for-one. Third, the model passes our out-of-sample test. Given parameters calibrated to match 2017 data, the model quantitatively matches the runup in the fed funds rate in 2018 when we feed in the observed changes in repo rates. According to the model, the rise in the fed funds rate in 2018 can be completely explained by changes in repo rates. There is no need to assume that the scarcity value of reserves increased as a result of a reduced supply of reserves. Finally, we find that a reduction in deposit insurance premiums would increase the fed funds rate, but by only a small fraction of the change in the premium on most days.

The paper proceeds as follows. Section 2 provides background on the evolution of the federal funds market over the past decade. Section 3 describes the model. Section 4 uses information on the observed federal funds rate in 2017 and various regulations to calibrate the model parameters and to calculate bounds on the parameters under somewhat weaker assumptions. Section 5 shows that the model calibrated to 2017 data succeeds in quantitatively matching the pass-through of an increase in repo rates to the federal funds rate in 2018. Section 6 examines the effects of the scheduled reduction in deposit insurance premi-

ums. Section 7 discusses some possible interpretations of the bargaining power parameters that are at the core of the model. Section 8 concludes.

\section{Background}

The nature of the federal funds market today has changed dramatically relative to the period prior to the financial crisis. In the pre-crisis period, the Federal Reserve did not have the authority to pay interest on reserves. As a result, banks' demand for reserves stemmed largely from mandatory reserve requirements and the desire to avoid penalties for any deficiency in meeting these requirements. In that environment, the economic value of reserves at the margin was determined largely by the aggregate quantity of reserves supplied by the Federal Reserve relative to banks' aggregate demand for reserves. While the aggregate quantity of reserves supplied each day closely matched estimates of the aggregate demand for reserves, the reserve positions of individual banks on any given day could be strongly affected by shocks stemming from payments inflows and outflows on behalf of customers. Toward the end of the day, some banks would be left with larger quantities of reserves than they 
desired, while other banks would be left short of their desired end-of-day reserve positions. The banks that were short reserves then had a strong incentive to borrow in the federal funds market to avoid the risk of a reserve requirement deficiency. And the banks that were left with larger-than-desired end-of-day reserve positions had a strong incentive to lend to avoid holding large quantities of a non-interest-bearing asset. In short, the pre-crisis federal funds market involved active interbank trading as a mechanism that allowed banks to offset the unexpected shocks to their reserve positions in an environment where the aggregate quantity of reserves was set close the estimated aggregate demand for reserves at the target federal funds rate.

The current activity in the federal funds market is entirely different. In responding to the financial crisis, the Federal Reserve engaged in a series of large scale asset purchase programs that dramatically expanded the size of its balance sheet, from less than $\$ 1$ trillion in total assets in 2007 to about $\$ 4.5$ trillion today. That expansion in Federal Reserve assets was associated with an enormous increase in the level of reserves in the banking system. Prior to the crisis, the level of reserves in the banking system amounted to only about $\$ 20$ billion. Today, reserve balances are about $\$ 2$ trillion (Board of Governors of the Federal Reserve System, 2018).

In this environment of superabundant reserves, the key factor that led to active interbank trading in the funds market in the pre-crisis period - unexpected payments flows among banks - no longer provides a strong incentive for interbank trading. Unexpected payments flows are still present, but most banks hold such large quantities of reserves that even sizable outflows on any given day pose essentially no risk of a reserve requirement deficiency. Moreover, the Federal Reserve now pays interest on reserves. As a result, a bank that experiences a large reserve inflow no longer has a strong incentive to lend reserves at a rate below that it can earn by leaving balances at the Fed. As a result, interbank trading in the federal funds market is now very small and idiosyncratic. The remaining volume in the federal funds market reflects activity in which banks borrow on an overnight basis from GSEs - principally the Federal Home Loan Banks (FHLBs) - that are not eligible to earn interest on their balances at the Federal Reserve but that can participate in the federal funds market. In effect, the federal funds market is now just another overnight funding source for 
banks, and the volume of activity in the market is determined by the interaction between bank funding needs and the availability of funding from nonbank lenders.

Another important change in the post-crisis environment is that the Federal Reserve has implemented the ON RRP facility, which is available to a wide array of lenders in overnight funding markets - banks, primary dealers, Federal Home Loan Banks and other GSEs, and money market mutual funds (MMMFs). The ON RRP program allows these entities to place overnight funds at the Federal Reserve at a predetermined rate currently set 25 basis points below the IOER rate. The ON RRP rate thus creates a floor on the rate at which these entities will lend to others in private funding markets. As a result, the ON RRP program and the ON RRP rate potentially exert a strong influence over the level of the rates observed in both secured and unsecured overnight funding markets.

These changes in the micro structure of the federal funds market in turn have surfaced important interactions between activity in the federal funds market and the intermediation costs faced by different types of banks. In particular, branches and agencies of foreign banks operating in the United States make up a substantial share of the borrowing activity in the federal funds market. The volume of borrowing by domestic commercial banks, by contrast, is relatively small. Moreover, there are predictable patterns in the behavior of the federal funds rate, with the rate typically dropping substantially at month-ends and quarter-ends, as Figure 1 shows. Volume in the federal funds and other overnight funding markets often falls sharply on these days, and volume at the Federal Reserve's ON RRP facility often increases sharply.

Month-end and quarter-end changes in rates and volumes in the federal funds market are short lived, but they provide some important clues about how various bank regulatory policies may be affecting bank asset-liability management and the behavior of overnight rates in bank funding markets. For example, domestic commercial banks generally must meet a leverage ratio requirement based on their average total assets maintained over a quarter. Moreover, these institutions are subject to Federal Deposit Insurance Corporation (FDIC) deposit insurance premiums that are also based on average total assets maintained over a quarter. In contrast, most foreign branches are not FDIC insured and thus do not pay deposit insurance premiums. In addition, many of these institutions are subject to a leverage ratio 
requirement based on month-end or quarter-end assets rather than daily average assets.

A number of papers have pointed to these differences in the regulatory treatment of domestic and foreign institutions as a key factor explaining the current behavior of the federal funds market. (See, e.g., Keating and Macchiavelli, 2017.) Because domestic banks face higher costs on most days in the form of deposit insurance premiums and a leverage ratio based on daily-average assets, they are not able to post bids for funds that compete effectively with bids from foreign branches. Without deposit insurance premiums or a leverage ratio constraint to worry about on most days, even a small spread between IOER and the federal funds rate provides a positive return to a foreign branch borrowing in the funds market but is not enough to allow domestic banks to cover deposit insurance premiums and the implicit capital costs stemming from the leverage ratio requirement. On month-ends and quarterends, foreign branches are concerned about the size of their balance sheets and actively seek to reduce their required capital by paring the size of their balance sheets on those days.

But regulatory balance sheet costs are likely not the only factor determining the federal funds rate. As discussed, foreign banks effectively have no marginal cost of borrowing reserves at mid-month. If there were perfect competition among foreign banks for the opportunity to borrow from fed funds from FHLBs, the FHLBs would drive the borrowers to their reservation price, IOER. In practice, this does not happen; the fed funds rate is significantly below IOER even at mid-month, implying that the borrowing banks have some market power that allows them to pay less than their reservation price. Our model provides a quantitative framework for understanding how the interplay between balance sheet costs and bargaining power determines the fed funds rate and its dynamics over time.

\section{Model}

This section describes the economic environment and the bargaining problem between banks and a non-bank investor, then solves for the equilibrium federal funds rate as a function of banks' balance sheet costs, the investor's alternative investment options, and banks' bargaining power. 


\section{A. Environment}

We assume the market contains three agents: a representative GSE investor, a representative domestic bank, and a representative foreign bank. In reality, of course, there are multiple institutions of each of these types. The model abstracts from the heterogeneity and competition within these groups in order to highlight the role of differences across the groups, such as the different balance sheet costs of foreign vs. domestic banks. However, the model contains parameters that, as we discuss further in section 6, might be taken to reflect the strength of competition within each group.

The non-bank has reserves that earn zero interest if kept in its own reserve account, but the non-bank can also invest these reserves in repurchase agreements, or repo, or can lend them to either the domestic or the foreign bank in the federal funds market.

A repo can be conducted with the Federal Reserve's overnight reverse repurchase agreement (ON RRP) facility at the annual interest rate onrrp or with a private counterparty at the market rate reро. Let repo* $=\max \{$ onrrp, repo $\}$ denote the higher of these two rates. We take the market repo rate as exogenous and do not model its determination.

Both domestic and foreign banks earn interest on reserves at the annual interest rate ioer. If reserves are abundant, this is the only return on reserves. We also consider the possibility that reserves are not abundant and have a scarcity value $z \geq 0$ associated with their usefulness in meeting payment obligations or satisfying regulatory requirements. A bank's total return on reserves is therefore ioer $+z$. In most of the analysis, we will take $z$ to be 0 for all banks, reflecting the current abundance of reserves, but it would be possible to apply the model to situations where $z$ is positive for domestic banks, foreign banks, or both.

Domestic $(d)$ and foreign $(f)$ banks differ in their balance sheet costs. Balance sheet costs are calculated over a regulatory time period. In our benchmark calibration, this time period will be a quarter, but it could also be a month. The regulatory time period has $T$ days - if the regulatory period is a quarter, $T=90$, and if the regulatory period is a month, $T=30$. Each bank $i \in\{d, f\}$ pays a per-regulatory-period cost that depends on some combination of its daily average assets and its assets at the end of the period. Let $A_{i, t}$ be the assets of bank $i$ on day $t \in\{1,2, \ldots, T\}$ of the period. The balance sheet cost of bank $i$ for 
the entire regulatory period, expressed in dollars, is

$$
C_{i}\left(\left\{A_{i, t}\right\}_{t=1}^{T}\right)=\tau_{i}\left[\theta_{i} \frac{1}{T} \sum_{t=1}^{T} A_{i, t}+\left(1-\theta_{i}\right) A_{i, T}\right]
$$

where we assume $\theta_{i} \in[0,1]$.

The parameter $\theta_{i}$ indexes the extent to which bank $i$ 's balance sheet cost depends on daily average assets vs. period-end assets. If $\theta_{i}=1$, the balance sheet cost depends only on daily average assets, while if $\theta_{i}=0$, the balance sheet costs depends only on period-end assets. The parameter $\tau_{i}>0$ measures how balance sheet costs respond to changes in assets. Both $\theta_{i}$ and $\tau_{i}$ should be interpreted as reflecting both formal regulations and less formal costs of balance sheet. For example, even if a bank faces only daily-average regulations, it still might be concerned about shareholders' reaction to quarter-end balance sheet numbers published in financial statements and thus have $\theta_{i}<1$. Even if a bank faces only quarterend regulations, it might be concerned about mid-quarter balance sheet if there are costs of adjustment not explicitly included in our model and thus have $\theta_{i}>0$.

We assume that banks can adjust their assets on a daily basis. The marginal cost of expanding the balance sheet by $\$ 1$ on day $t$, expressed in dollars, is therefore

$$
\frac{\partial C_{i}}{\partial A_{i, t}}=\tau_{i}\left[\frac{1}{T} \theta_{i}+\left(1-\theta_{i}\right) \mathbb{1}(t=T)\right]
$$

where we define $\mathbb{1}(t=T)$ to equal 1 when $t=T$ and equal 0 otherwise. It is useful to express the marginal cost as an annual interest rate:

$$
m c_{i t}=360 \frac{\partial C_{i}}{\partial A_{i, t}}=360 \tau_{i}\left[\frac{1}{T} \theta_{i}+\left(1-\theta_{i}\right) \mathbb{1}(t=T)\right]
$$

We assume that

$$
\tau_{d}>\tau_{f}
$$

and

$$
\theta_{d}>\theta_{f}
$$

In other words, the domestic bank has higher marginal balance sheet costs, but also balance 
sheet costs that depend more on daily average assets and less on period-end assets.

There are gains from trade when the investor lends to bank $i$ if and only if the bank's net return on reserves is greater than what the investor could earn in the repo market:

$$
\text { repo* }<\text { ioer }+z-m c_{i t} .
$$

The market will behave differently when there are gains from trade at both banks than when only one bank satisfies (6).

\section{B. Bargaining}

Each day, the non-bank investor bargains sequentially with the two banks over the interest rate on the investment. Specifically, the investor chooses one bank to bargain with first. If the investor and the bank agree on an interest rate, the investor leaves its funds with this bank for the night. If they do not agree, the investor can bargain with the second bank - but if this second round of bargaining fails, it is not allowed to return to the first bank and must invest in repo.

The investor and the banks use Nash bargaining to agree on an interest rate. Nash bargaining means that the two parties - the investor and one of the banks — split the surplus, if any, from their transaction according to a prespecified bargaining weight. If no gains from trade are possible because (6) does not hold for the bank in question, no agreement is reached and the investor lends to a different bank or in repo.

Let $s_{i t}(r)$ be the surplus of bank $i$ on day $t$ if it borrows from the investor at rate $r$. Likewise, let $v_{i j t}(r)$ be the surplus of the investor if it lends to bank $i$ at rate $r$ in the $j$ th negotiation of day $t$ (where $j=1$ or 2 ). We will see that the investor's surplus depends both on which round of bargaining it is in and which bank it is negotiating with, even though it

always has the outside option of investing in repo. Let $\beta_{i} \in[0,1]$ be the bargaining weight of bank $i$ when bargaining with the investor. Nash bargaining assumes that, if gains from trade are possible, then the investor and the bank agree to a loan at the rate

$$
r_{i j t}^{*}=\arg \max _{r}\left[s_{i t}(r)\right]^{\beta_{i}}\left[v_{i j t}(r)\right]^{1-\beta_{i}} .
$$


To find the equilibrium interest rate, we need to define the surplus functions $s_{i t}(r)$ and $v(r)$. If a bank reaches no agreement, it earns nothing; if it reaches an agreement, it earns ioer and receives the scarcity value $z$ but pays its balance sheet cost and the rate owed to the investor. The bank's surplus is the difference between the profit if an agreement is reached and the outside option of earning nothing - so the surplus is ioer $+z$ minus the balance sheet cost minus the fed funds rate. Thus

$$
s_{i t}(r)=i o e r+z-m c_{i t}-r .
$$

Meanwhile, the surplus of the investor is the difference between the interest rate it receives and what it could get if it abandons this negotiation and pursues other options. Let $\underline{r}_{i j t}$ be the investor's outside option when bargaining with bank $i$ in the $j$ th negotiation on day $t$. The outside option is different in the first round $(j=1)$ than in the second round because after the first round, the outside option still includes the possibility of negotiating with another bank, whereas in the second round the only outside option is repo. And in the first round, the investor's outside option depends on which bank is being negotiated with because abandoning the negotiation with one bank implies the option to negotiate with the other bank.

With this notation, if bank $i$ and the investor are bargaining on day $t$, if this is the investor's $j$ th negotiation of the day, and if (6) holds for bank $i$, the interest rate they agree on is:

$$
\begin{aligned}
r_{i j t}^{*} & =\arg \max _{r}\left[\text { ioer }+z-m c_{i t}-r\right]^{\beta_{i}}\left[r-\underline{r}_{i j t}\right]^{\left(1-\beta_{i}\right)} \\
& =\left(1-\beta_{i}\right)\left[\text { ioer }+z-m c_{i t}\right]+\beta_{i} \underline{r}_{i j t} .
\end{aligned}
$$

There is an important distinction in this framework between a party's bargaining weight and its outside option. The outside option is what a party can get if it reaches no agreement. A party with a better outside option gets a better deal because otherwise it will prefer not to agree. The bargaining weight is how the parties divide the surplus, taking their outside options as given. As a party's bargaining weight increases, it gets a larger share of the surplus, even though there is no change in the outside option it will get without an 
agreement. The bargaining weight of the single representative bank of type $i$ may be taken as reflecting the amount of competition among the multiple real-world banks of that type for example, if there are many foreign banks, we would expect each of them to have little bargaining power, holding fixed the outside option of any foreign bank.

\section{Solution}

Three cases are possible on any given day: there may be gains from trade at neither bank, at only one bank, or at both banks. We consider these possibilities in turn.

\section{Gains from trade at neither bank}

If there are no gains from trade at either bank on a given day, then the investor cannot reach agreement when bargaining with either bank. The investor uses repo, and the fed funds market does not operate on that day.

\section{Gains from trade at only one bank}

If there are gains from trade at only one bank on a given day, the investor will bargain with that bank. If the negotiation fails, the investor will turn to repo because there is no possibility of an agreement with the other bank. Let $i_{t}^{*}$ be the bank where there are gains from trade. The investor's outside option when bargaining with that bank is $\underline{r}_{i}, 1 t=\operatorname{repo}^{*}$. The equilibrium fed funds rate is the rate that the investor and bank $i_{t}^{*}$ agree on:

$$
r_{t, 1 \text { bank }}^{*}=r_{i_{t}^{*}, 1 t}^{*}=\left(1-\beta_{i_{t}^{*}}\right)\left(\text { ioer }+z-m c_{i_{t}^{*}, t}\right)+\beta_{i_{t}^{*}} \text { repo }^{*}
$$

If there are gains from trade at only one bank, then the fed funds rate depends on the bargaining power and balance sheet costs of that bank, as well as on ioer and repo*, but is not influenced by the bargaining power and balance sheet costs of the bank where there are no gains from trade.

The influence of ioer and repo* depends on the bank's bargaining power. When the bank has high bargaining power, it drives the investor close to the investor's outside option, which is repo; thus, the passthrough of the repo rate to the fed funds rate is high, and the passthrough of ioer is low. Conversely, when the bank has low bargaining power, the investor drives the bank close to its outside option, which is ioer minus marginal cost; the passthrough 
of the repo rate is low, and the passthrough of ioer is high. The scarcity value $z$ has the same effect on the fed funds rate as ioer.

\section{Gains from trade at both banks}

If there are gains from trade at both banks on a given day, two rounds of negotiations become possible - the investor can turn to the second bank if negotiations with the first bank fail. Consider first what happens in the second negotiation of the day $(j=2)$, if it occurs. The investor's outside option in this case is to put the funds in repo. Therefore $\underline{r}_{i 1 t}=r e p o^{*}$, and

$$
\begin{aligned}
r_{i 2 t}^{*} & =\arg \max _{r}\left[\text { ioer }+z-\frac{1}{T} \tau_{i} \theta_{i}-\tau_{i}\left(1-\theta_{i}\right) \mathbb{1}(t=T)-r\right]_{i}^{\beta}\left[r-\text { repo }^{*}\right]^{\left(1-\beta_{i}\right)} \\
& =\left(1-\beta_{i}\right)\left[\text { ioer }+z-\frac{1}{T} \tau_{i} \theta_{i}-\tau_{i}\left(1-\theta_{i}\right) \mathbb{1}(t=T)\right]+\beta_{i} \text { repo* } \\
& =\left(1-\beta_{i}\right)(\text { ioer }+z)+\beta_{i} \text { repo }^{*}-\left(1-\beta_{i}\right) m c_{i t} .
\end{aligned}
$$

Now consider the first negotiation of the day. The investor's outside option is to pursue a second negotiation, in which case it can get $r_{-i, 2 t}^{*}$, where $-i$ is the bank that is not negotiated with first. Therefore,

$$
\begin{aligned}
r_{i 1 t}^{*}= & \left(1-\beta_{i}\right)\left[\text { ioer }+z-\frac{1}{T} \tau_{i} \theta_{i}-\tau_{i}\left(1-\theta_{i}\right) \mathbb{1}(t=T)\right]+\beta_{i} r_{-i, 2 t}^{*} \\
= & \left(1-\beta_{i}\right)\left[\text { ioer }+z-\frac{1}{T} \tau_{i} \theta_{i}-\tau_{i}\left(1-\theta_{i}\right) \mathbb{1}(t=T)\right] \\
& \quad+\beta_{i}\left(1-\beta_{-i}\right)\left[\text { ioer }+z-\frac{1}{T} \tau_{-i} \theta_{-i}-\tau_{-i}\left(1-\theta_{-i}\right) \mathbb{1}(t=T)\right]+\beta_{i} \beta_{-i} \text { repo }{ }^{*} \\
& \quad\left(1-\beta_{d} \beta_{f}\right)(\text { ioer }+z)+\beta_{d} \beta_{f} \text { repo }^{*}-\left(1-\beta_{i}\right) m c_{i t}-\beta_{i}\left(1-\beta_{-i}\right) m c_{-i, t} .
\end{aligned}
$$

Which bank should the investor bargain with first? Since (6) holds for both banks, $r_{i 1 t}^{*}>r_{i 2 t}^{*}$ so if the investor is going to lend to bank $i$, it prefers to do so in the first round of bargaining. Therefore, the investor will maximize its profit by first bargaining with the bank that has the higher $r_{i 1 t}^{*}$ (and agreeing to this bargain rather than moving to the other bank). The difference in first-round rates between the foreign and domestic banks is proportional to 
the difference in their marginal costs:

$$
\begin{aligned}
r_{f 1 t}^{*}-r_{d 1 t}^{*} & =\left(1-\beta_{f}\right)\left(1-\beta_{d}\right)\left[\frac{\tau_{d} \theta_{d}-\tau_{f} \theta_{f}}{T}+\left[\tau_{d}\left(1-\theta_{d}\right)-\tau_{f}\left(1-\theta_{f}\right)\right] \mathbb{1}(t=T)\right] \\
& =\left(1-\beta_{f}\right)\left(1-\beta_{d}\right)\left(m c_{d t}-m c_{f t}\right) .
\end{aligned}
$$

Thus, the investor lends each day to whichever bank has the lower marginal balance sheet cost on that day. Let $i_{t}^{*}$ be this bank, and let $-i_{t}^{*}$ be the other bank. Then the equilibrium interest rate is

$$
r_{t, 2 \text { banks }}^{*}=\left(1-\beta_{d} \beta_{f}\right)(\text { ioer }+z)+\beta_{d} \beta_{f} r e p o^{*}-\left(1-\beta_{i_{t}^{*}}\right) m c_{i_{t}^{*}, t}-\beta_{i_{t}^{*}}\left(1-\beta_{-i_{t}^{*}}\right) m c_{-i_{t}^{*}, t} .
$$

If there are gains from trade at both banks, then the fed funds rate depends on the bargaining power and balance sheet costs of both banks, even though the investor lends only

to one of the banks - the one with the lower marginal balance sheet cost. The passthrough of other interest rates to the fed funds rate depends on the combined bargaining power of the two banks, $\beta_{d} \beta_{f}$ : When combined bank bargaining power is high, the passthrough of repo* is high, and when combined bank bargaining power is low, the passthrough of ioer is high. Just as when there are gains from trade at only one bank, the scarcity value $z$ has the same effect on the fed funds rate as ioer.

If the bank with the lower marginal cost has no bargaining power $\left(\beta_{i_{t}^{*}}=0\right)$, equation (14) reduces to

$$
r_{t}^{*}=i o e r+z-m c_{i_{t}^{*}, t}
$$

which is the outcome under perfect competition - the price of intermediation in the fed funds market is set equal to its marginal cost, $m c_{i_{t}^{*}, t}$.

\section{Understanding end-of-period rate movements}

According to the model, three factors determine how the fed funds rate changes at the end of the regulatory period. First, marginal balance sheet costs change at the end of the period. Second, because marginal balance sheet costs change, the identity of the lowest-cost bank can change, and the influence of each bank's bargaining power on the fed funds rate 
depends on whether that bank is the lowest-cost bank. Finally, if repo rates move on the last day of the period for reasons outside the model, that movement will pass through partially to the fed funds rate.

\section{Parameter values}

The model has eight parameters: $\beta_{d}, \theta_{d}, \tau_{d}, \beta_{f}, \theta_{f}, \tau_{f}, T, z$. We calibrate these parameters based on observed interest rates and known information about balance sheet costs and regulations. Beyond the calibration, we look for bounds on possible values of the parameters given observed interest rates. We calibrate the model to data from 2017; later, we will test the model's predictions out of sample in 2018 data. Because reserves were generally agreed to be super-abundant in 2017, we assume that the scarcity value of reserves $z$ was zero in that year and search for values of the other seven parameters.

\section{A. Calibration}

Domestic banks are generally regulated based on daily average assets, while foreign banks are generally regulated based on either quarter-end or month-end assets. This suggests that the regulatory period should be either one quarter $(T=90)$ or one month $(T=30)$. However, Figure 1, shows that the behavior of the fed funds rate in 2017 was the same at all month-ends, whether they fell at the end of a quarter or not. If we set $T=90$, the model could not explain this pattern because balance sheet costs would be the same at mid-quarter month-ends as on days in the middle of a month. We therefore set $T=30$.

In line with the regulations, we assume that domestic banks care only about daily average assets $\left(\theta_{d}=1\right)$ and that foreign banks care only about period-end assets $\left(\theta_{f}=0\right)$.

Balance sheet costs potentially stem from leverage ratio requirements as well as FDIC assessments. Foreign banks typically are not subject to FDIC assessments, $]^{1}$ while domestic banks are assessed a percentage of daily average assets. We set the domestic FDIC assessment at an annual interest rate of $0.07 \%$, the average value estimated by Banegas and Tase (2016).

Foreign banks typically have a required leverage ratio - the ratio of equity to total

\footnotetext{
${ }^{1}$ Few foreign banks apply for deposit insurance. Those that do apply for deposit insurance are subject to FDIC assessments and should be treated as having the same balance sheet costs as domestic banks in our framework.
} 
assets - of 3\% under Basel III. If this is a binding constraint, if the required return on equity is $10 \%$, and if equity must be held for an entire month, then each additional $\$ 100$ of borrowing on the last day of the period costs the foreign bank $\$ 0.30 / 12=\$ 0.025$. Expressed as an annual interest rate, the cost is $9 \%$, far in excess of the 25-basis-point spread between ioer and onrrp. Even very short holding periods and near-zero required returns on equity do not change the basic conclusion that an end-of-period leverage ratio requirement eliminates all gains from trade in lending to foreign banks at the end of the regulatory period. For example, a one-month holding period and a return on equity of just 50 basis points implies costs of 45 basis points at an annual interest rate, while a two-day holding period and a return on equity of $5 \%$ implies costs of 30 basis points at an annual interest rate. We therefore do not choose a specific value for foreign bank balance sheet costs but simply assume that they are high enough to eliminate foreign borrowing at period end: $360 \tau_{f}>0.25 \%$.

The largest domestic banks can have a required leverage ratio of $6 \%$ due to the supplementary leverage ratio. But it is not clear that this constraint is binding. Call report data show that all of the domestic banks subject to a $6 \%$ leverage ratio requirement reported a ratio well above that threshold as of the end of 2017 (Federal Financial Institutions Examination Council, 2017). Furthermore, the same calculus as for foreign banks implies that a binding leverage ratio constraint would drive domestic banks out of the fed funds market for any reasonable return on equity: If the $6 \%$ leverage ratio were binding for domestic banks, then any required return above $4.2 \%$ would produce a balance sheet cost above 25 basis points. Since in practice the fed funds market does not shut down at month ends, we conclude that the leverage ratio is not a binding constraint for domestic banks and that their only balance sheet cost relevant to our model is the FDIC assessment. This requires $m c_{d t}=0.07 \%$ and hence $\tau_{d}=0.07 \% \times(T / 360)$.

We now use information on observed interest rates to find the values of $\beta_{d}$ and $\beta_{f}$. Since the Federal Open Market Committee began the process of normalizing interest rates in December 2015, ioer has always been set 25 basis points above onrrp. Further, before 2018, repo rates remained very close to onrrp, and the minor differences between market repo rates and onrrp could have been due to details such as the nature of the counterparties or the time of day of the transactions. For simplicity, therefore, we assume that the ON RRP facility was 
Table 1: Distribution of the difference between the federal funds rate and the interest rate on excess reserves, 12/17/2015-4/25/2018

\begin{tabular}{lrrr}
\hline Statistic & Quarter-end & Other month-end & All other days \\
\hline $12 / 17 / 2015-12 / 14 / 2016$ & & & \\
mean & -24.0 & -20.1 & -11.4 \\
minimum & -30.0 & -21.0 & -15.0 \\
maximum & -20.0 & -19.0 & -9.0 \\
observations & 4 & 8 & 238 \\
$12 / 15 / 2016-12 / 13 / 2017$ & & & \\
mean & -19.0 & -17.9 & -9.0 \\
minimum & -20.0 & -19.0 & -9.0 \\
maximum & -18.0 & -17.0 & -8.0 \\
observations & 4 & 8 & 239 \\
$12 / 14 / 2017-5 / 14 / 2018$ & & & \\
mean & -12.5 & -12.3 & -7.1 \\
minimum & -17.0 & -16.0 & -9.0 \\
maximum & -8.0 & -6.0 & -5.0 \\
observations & 2 & 3 & 99 \\
\hline
\end{tabular}

All values in basis points.

the best repo option during the calibration period: repo* $=$ onrrp .

Table 1 shows the distribution of the effective federal funds rate relative to ioer during the current tightening cycle. During the first year after normalization began, from the December 2015 FOMC meeting to the December 2016 meeting, the fed funds rate displayed some volatility even at mid-month, as illustrated in Figure 1. But in the second year, from the December 2016 to December 2017 FOMC meetings, the fed funds rate was almost exactly 16 basis points above onrrp and 9 basis points below ioer at mid-month, and typically 18 basis points below ioer at month- or quarter-end. We calibrate the model to match that second year of data, then ask whether it can explain the substantially different pattern of rates since the December 2017 FOMC meeting.

Our calibrated balance sheet costs imply that there are gains from trade when the investor lends to either bank at mid-month, while at month-end there are gains from trade only when the investor lends to the domestic bank. Thus, the equilibrium fed funds rate satisfies (14) at mid-month (with $i_{t}^{*}=f$ ) and satisfies 10 at month-end (with $i_{t}^{*}=d$ ). 
Hence we require the parameters to satisfy

$$
\begin{gathered}
\text { ioer }-0.0009=\left(1-\beta_{d} \beta_{f}\right)(\text { ioer }+z)+\beta_{d} \beta_{f} \text { repo }^{*} \\
-\left(1-\beta_{f}\right) m c_{f, t<T}-\beta_{f}\left(1-\beta_{d}\right) m c_{d, t<T} \\
\text { ioer }-0.0018=\left(1-\beta_{d}\right)\left(\text { ioer }+z-m c_{d T}\right)+\beta_{d} \text { repo }{ }^{*}
\end{gathered}
$$

The solution to these equations is shown in Table 2, along with the other parameter values are. The foreign bank captures exactly half the surplus when it negotiates with the investor, while the domestic bank captures slightly more than half. Intuitively, given that the foreign bank has no balance sheet cost at mid-month, its bargaining weight must be 0.5 because the fed funds rate at mid-month is halfway between ioer and the month-end rate, and the month-end rate - paid by domestic banks - represents what the investor could receive if it abandoned negotiations with the foreign bank.

The calibrated bargaining weights have direct implications for the influence of repo rates on the fed funds rate. At month end, according to (10), each basis point change in repo* moves the fed funds rate by $\beta_{d}$, or 0.61 basis point in our calibration. At mid-month, according to (14), the pass-through is weaker: Each basis point change in repo* moves the fed funds rate by $\beta_{d} \beta_{f}$, or 0.31 basis point in our calibration.

\section{B. Bounds}

The observed interest rates allow us to find some bounds on the model parameters while making only minimal assumptions about balance sheet costs. If both banks had maximal bargaining power, $\beta_{d}=\beta_{f}=1$, the fed funds rate would be driven down to onrrp regardless of balance sheet costs. That the rate is not driven so low gives us an upper bound on banks' bargaining power. Conversely, if neither bank had any bargaining power, $\beta_{d}=\beta_{f}=0$, the fed funds rate would be driven up to ioer $+z$ minus the lowest marginal balance sheet cost

on any given day. That the fed funds rate does not rise all the way to ioer shows that banks must have some bargaining power or balance sheet costs.

To make this analysis quantitative, we assume that the parameters satisfy several conditions. First, we fix $T=30, z=0, \theta_{d}=1$, and $\theta_{f}=0$. Second, we continue to assume 
Table 2: Calibrated parameter values

\begin{tabular}{lr}
\hline Parameter & Value \\
\hline \multicolumn{2}{c}{ Scarcity value of reserves } \\
$z$ & 0 \\
Asset calculation & 30 \\
$T$ & 1 \\
$\theta_{d}$ & 0 \\
$\theta_{f}$ & \\
Balance sheet costs \\
\multicolumn{2}{c}{$0.0007 \times T / 360$} \\
$\tau_{d} \quad>0.0025 / 360$ \\
Bargaining weights \\
$\beta_{d}$ & 0.611 \\
$\beta_{f}$ & 0.5 \\
\hline
\end{tabular}

that $360 \tau_{f}>0.25 \%$, so the foreign bank never borrows at month-end. Third, we assume domestic balance sheet costs are non-negative. We then seek bounds on $\beta_{d}, \beta_{f}$ and $\tau_{d}$.

The foreign bank's bargaining weight $\beta_{f}$ is sharply identified, using the same intuition given for our calibrated parameter values. Regardless of the domestic bank's balance sheet costs and bargaining weight, the investor's outside option at mid-month if it does not bargain with the foreign bank is to receive the month-end rate 18 basis points below ioer. Since the mid-month rate is 9 basis points below ioer, the foreign bank's bargaining weight must be 0.5 regardless of the remaining parameters.

The fact that the fed funds market operates at month-end gives us an upper bound on the domestic bank's balance sheet costs: they must not be larger than the observed spread between ioer and the fed funds rate at month end, or 18 basis points at an annual interest rate. Thus

$$
\tau_{d} \leq 0.0018 \times T / 360
$$

FDIC assessments on large banks depend on a regulatory scorecard but at present are never less than 6 basis points (Federal Deposit Insurance Corporation, 2018), which provides a 
lower bound on the domestic balance sheet costs:

$$
\tau_{d} \geq 0.0006 \times T / 360
$$

Applying (10) at month end gives us a fixed relationship between $\tau_{d}$ and $\beta_{d}$ given the other parameters:

$$
\beta_{d}=\frac{0.0018-360 \tau_{d} / T}{0.0025-360 \tau_{d} / T}
$$

Combining (17), 18), and (19) gives us bounds on the domestic bank's bargaining power:

$$
0 \leq \beta_{d} \leq 0.632
$$

These bounds on the domestic bank's bargaining power in turn imply bounds on the passthrough of repo rates to the fed funds rate: between 0 and $63.2 \%$ at month-end, and between 0 and $31.6 \%$ at mid-month.

\section{Out-of-sample test: interest rates in 2018}

Figure 1 shows that, since the December 2017 FOMC meeting, both the fed funds rate and repo rates have risen substantially within the range delimited by onrrp and ioer. We take the rise in the repo rate as exogenous - market commentary has largely attributed it to increased issuance of Treasury bills — and ask two questions. First, using the 2017 parameters and the exogenous change in the repo rate, how well does the model fit the data on the fed funds rate in 2018? Second, does the model require any change in the scarcity value of reserves to explain the rise in the fed funds rate, or can it fit the data while maintaining a scarcity value of zero - despite the roughly $\$ 200$ billion decrease in reserve supply since the Fed began normalizing its balance sheet?

On December 14, 2017, the first day after the December FOMC meeting, the Broad General Collateral Rate (BGCR) repo index stood at 1.28\%, 3 basis points above onrrp and 22 basis points below ioer 2 On April 25, 2018, the BGCR index had risen to 1.67\%, but onrrp had risen to only $1.50 \%$, so the spread had increased by 14 basis points. We take the

\footnotetext{
${ }^{2}$ BGCR data before April 2, 2018, are indicative historical values and not an official reference rate.
} 
initial 3-basis-point spread to onrrp as reflecting the price of different detailed characteristics of the broad repo market relative to the ON RRP facility and assume that repo* increased by 14 basis points more than onrrp and ioer over the period.

According to (14), if balance sheet costs and ioer are held fixed, a 1 basis point increase in repo* relative to ioer causes an increase of $\beta_{d} \beta_{f}$ in the fed funds rate relative to ioer. Our calibration has $\beta_{d} \beta_{f}=0.3056$. Thus, the model predicts that the rise in repo rates should have caused the fed funds rate to increase relative to ioer by 4.3 basis points. In the data, as shown in Figure 1 and Table 1 , the fed funds rate rose by 4 basis points relative to ioer, closely matching our out-of-sample prediction.

The model predicts a very slightly higher fed funds rate than actually occurred. The fed funds rate in the model is increasing in the scarcity value of reserves $z$, so the model does not need an increase in reserve scarcity to explain the rise in the fed funds rate in 2018. If anything, the model suggests that the scarcity value fell slightly.

Another notable feature of Figure 1 is a change in the month-end and quarter-end behavior of the fed funds rate. At the end of both March and April 2018, the fed funds rate fell by only 1 basis point, compared with drops of 9 basis points at previous month ends. Can the changing dynamics of repo rates help explain the different month-end behavior of the fed funds rate in March and April?

Recall that in the calibrated model, the pass-through of repo rates to the fed funds rate is different at month end than at mid-month because the foreign bank is not in the market at month-end. In particular, according to $(10)$, a 1 basis point increase in repo* at month-end causes an increase of $\beta_{d}$ in the fed funds rate relative to ioer. Our calibration has $\beta_{d}=0.611$. Thus, the calibrated model predicts that a 14 -basis-point increase in repo rates would raise the month-end fed funds rate by 8.6 basis points, or twice as much as the predicted 4.3-basis-point increase at mid-month. This implies that the generally higher level of repo rates should have resulted in a month-end fed funds rate drop of 4.7 basis points, significantly smaller than the 9-basis-point drops observed in 2017.

In fact, the month-end drop was just 1 basis point in both March and April, so the generally higher level of repo rates explains not quite half of the change in month-end dynamics. But in addition, repo rates rose at the end of March and April, whereas in 2017 
repo rates were typically stable at month ends. For example, on the last day of April, the BGCR rate rose by 4 basis points compared with the previous trading day. In the calibrated model, a 4-basis-point increase in repo* at month end predicts an additional 2.4 basis point increase in the fed funds rate. Thus, combining the generally higher level of repo rates and the newly observed month-end rises in repo rates, the model predicts a month-end fed funds rate drop of 2.3 basis points, quite close to the 1-basis-point drop in the data.

We can use the model to estimate the scarcity value of reserves. For any day, we can solve for the value of $z$ such that (14) (for mid-month) or (10) (for month-end) holds, given observed interest rates and the calibrated values of the other parameters. The calculation requires a daily value for repo*, and we cannot just take the higher of the BGCR rate or the rate at the ON RRP facility because market repo may have different liquidity or risk characteristics than a repo investment with the Fed. On most days in 2017, the BGCR rate was 1 to 3 basis points above the ON RRP rate and investments in the ON RRP facility exceeded $\$ 90$ billion (Federal Reserve Bank of New York, 2017). We therefore assume that a 3-basis-point spread of BGCR over onrrp makes investors indifferent between the two investments and set repo* $=\max \{$ onrrp, $B G C R-0.0003\}$. On two Good Friday holidays when the fed funds market was open but the repo market was closed, we set repo* to the previous day's value, on the assumption that investors could have made forward-looking decisions about whether to place funds in the repo market or in fed funds over the holiday weekend.

Figure 2 shows the calculated value of $z$. During the period between the December 2016 and December 2017 FOMC meetings that we use to calibrate the model, the scarcity value is generally almost exactly zero. However, the scarcity value drops below zero on a few dates when repo rates rose but the fed funds rate did not respond, most notably on June 30, 2017, when the BGCR rate rose 9 basis points above onrrp. The model interprets a rise in repo rates without a corresponding rise in the fed funds rate as a decrease in the scarcity value because if the scarcity value were constant, higher repo rates would raise the fed funds rate. An alternative interpretation, outside the model, is that the elevated repo rates embedded some risk or liquidity premium relative to the ON RRP facility on those dates. Consistent with this alternative interpretation, total investment in the ON RRP facility on June 30, 


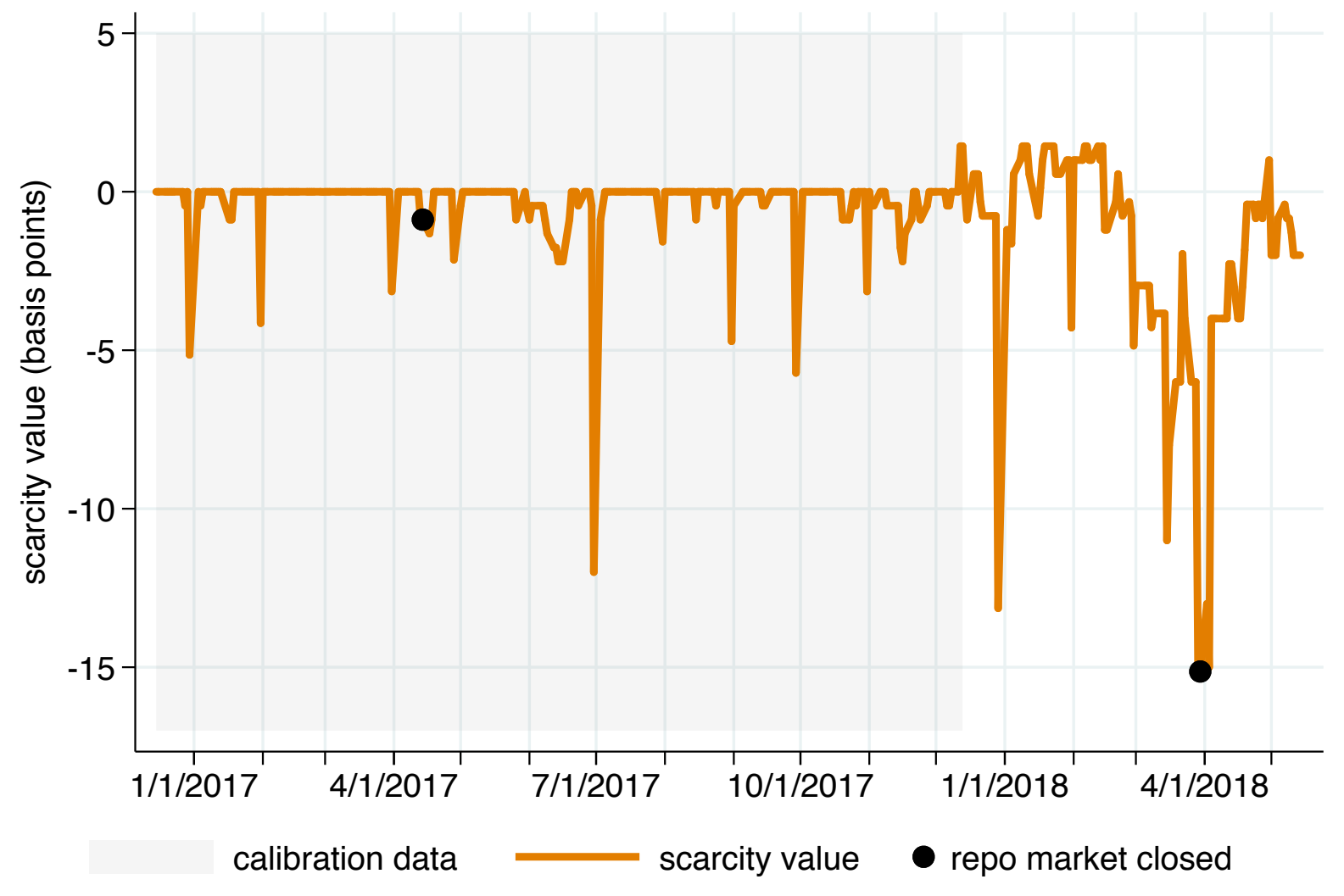

Figure 2: Implied scarcity value of reserves.

Source: Authors' calculations.

2017, was $\$ 399$ billion (Federal Reserve Bank of New York, 2017), the fourth-highest level ever observed and more than $\$ 100$ billion above the amounts invested in ON RRP on the immediate previous and subsequent days, suggesting that investors had some reason to prefer ON RRP to repo on that day even though the market repo rate significantly exceeded the rate at the ON RRP facility.

After the December 2017 FOMC meeting, the scarcity value becomes more volatile but remains within a few basis points of zero on almost all days. When the scarcity value deviates from zero, it is almost always negative, not positive, and on the few days when it is positive, it is just 1 basis point. Thus, the rise in repo rates is more than enough to explain the rise in the fed funds rate in 2018.

At the end of December 2017 and the end of March 2018, the scarcity value spikes sharply downward because repo rates rose but the fed funds rate did not move as much as 
the model predicts in response. Again, an alternative interpretation is that market repo investments carried an elevated risk or liquidity premium at those times.

\section{The effects of a reduction in deposit insurance premiums}

The FDIC currently collects a surcharge of 4.5 basis points (at an annual rate) on the assets of large domestic banks to raise money to increase its deposit insurance fund. This surcharge will end when the deposit insurance fund's assets reach a specified target or on December 31, 2018, whichever comes first (Federal Deposit Insurance Corporation, 2016). We can use our model to assess how the removal of the surcharge will affect the fed funds market and the EFFR.

Under our calibration, reducing domestic banks' FDIC assessment by 4.5 basis points would cut their balance sheet cost to 2.5 basis points at an annual rate. That cost would still leave domestic banks as the low-cost borrower at month-end and foreign banks as the low-cost borrower at mid-month. However, the equilibrium interest rate will change - at month-end because the domestic borrower's costs are lower, and at mid-month because the outside option of investing with a domestic bank is more attractive and forces foreign banks to offer the investor a better deal.

According to (10), a reduction of 4.5 basis points in the domestic bank's balance sheet cost raises the fed funds rate that a domestic bank would pay — which is the equilibrium rate at month-end - by $\left(1-\beta_{d}\right) \times 4.5$ basis points, or 1.75 basis points with our calibrated value of $\beta_{d}=0.611$.

Turning to mid-month, according to (14), a reduction of 4.5 basis points in the domestic bank's balance sheet cost raises the fed funds rate that a foreign bank would pay by $\beta_{f}(1-$ $\left.\beta_{d}\right) \times 4.5$ basis points, or 0.88 basis points with our calibrated value of $\beta_{f}=0.5$.

The removal of the 4.5 basis point FDIC surcharge is hence predicted to increase the fed funds rate by a bit less than 2 basis points at month end and a bit less than 1 basis point at mid-month, all else equal. Importantly, our calculation assumes that the change in the FDIC assessment does not affect repo rates. If repo rates were to change as a result of the removal of the surcharge, the movement in repo rates would partially pass through to the fed funds rate and the total effect of the policy change would be larger. 


\section{Interpreting the bargaining power parameters}

The model makes it straightforward to consider the effect of changes in bargaining power on the fed funds rate. Suppose, for example, that the domestic bank has more bargaining power when it bargains with the investor: $\beta_{d}^{\prime}>\beta_{d}$. This directly changes the relationship between the domestic bank and the investor but affects the foreign bank only through the change in the investor's outside option. Specifically, the investor's outside option when bargaining with the foreign bank is now worse. As a result, the fed funds rate falls even when the investor lends to the foreign bank.

However, we must be careful in considering what constitutes an increase in domestic banks' bargaining power — it is an increase in market power among domestic banks. We will argue that such an increase would likely be associated with a reduction in the number of domestic banks competing in the fed funds market. A change that allowed more domestic banks to compete in the fed funds market would likely be associated with a decrease in their bargaining power. Thus, bargaining power is likely to be associated with the costs of entry into banking (or, more specifically, into the market for borrowing reserves from GSEs)

We formalize this argument by supposing that the economy contains $N$ banks, indexed by $i=1, \ldots, N$, each with bargaining weight $\beta_{i}$ and marginal cost of balance sheet $m c_{i t}$. To keep the notation simple, we set the scarcity value to $z=0$. Assume as before that the investor must bargain sequentially, choosing a bank to bargain with first, proceeding to another bank if it cannot reach an agreement with the first bank, and so on, but never returning to a bank after leaving it. Without loss of generality, we assume $\beta_{i}<1$ and $m c_{i t}<i$ oer - repo* for all $i$. (If some bank had a bargaining weight of 1 , it could capture all of the surplus when it negotiated with the investor, and so the investor would never negotiate with it. Likewise, an investor would never negotiate with a bank whose balance sheet costs exceeded the difference between IOER and repo rates. Thus, we can proceed as if such banks are not part of the economy.)

Let $i(j, t)$ be the identity of the bank that the investor chooses to bargain with in round $j$ on day $t$. If the investor reaches the last bank in the order, $j=N$, the investor's 
outside option is repo* and hence the interest rate will be

$$
r_{i(N, t), N, t}^{*}=\left(1-\beta_{i(N, t)}\right) i o e r+\beta_{i(N, t)} \operatorname{repo}^{*}-\left(1-\beta_{i(N, t)}\right) m c_{i(N, t), t} .
$$

This interest rate becomes the investor's outside option if it bargains with the next-to-last bank. Thus, if the investor reaches the next-to-last bank, the interest rate will be

$$
\begin{aligned}
r_{i(N-1, t), N-1, t}^{*}= & \left(1-\beta_{i(N-1, t)}\right) \text { ioer }+\beta_{i(N-1, t)} r_{i(N, t), N, t}^{*}-\left(1-\beta_{i(N-1, t)}\right) m c_{i(N-1, t), t} \\
= & \left(1-\beta_{i(N-1, t)} \beta_{i(N, t)}\right) \text { ioer }+\beta_{i(N-1, t)} \beta_{i(N, t)} \text { repo }^{*} \\
& \quad-\beta_{i(N-1, t)}\left(1-\beta_{i(N, t)}\right) m c_{i(N, t), t}-\left(1-\beta_{i(N-1, t)}\right) m c_{i(N-1, t), t} .
\end{aligned}
$$

By induction, the interest rate when the investor negotiates with the first bank is

$$
\begin{aligned}
r_{i(1, t), 1, t}^{*}=\left(1-\Pi_{j=1}^{N} \beta_{i(j, t)}\right) & \text { ioer }+\left(\Pi_{j=1}^{N} \beta_{i(j, t)}\right) \text { repo }^{*} \\
& -m c_{i(1, t), t}\left(1-\beta_{i(1, t)}\right)-\sum_{j=2}^{N} m c_{i(j, t), t}\left(1-\beta_{i(j, t)}\right) \Pi_{k=1}^{j-1} \beta_{i(k, t)} .
\end{aligned}
$$

The investor chooses a bargaining order so as to maximize $r_{i(1, t), 1, t}^{*}$. Consider swapping the first and second banks in the bargaining order, leaving all other banks in place. The resulting change in $r_{i(1, t), 1, t}^{*}$ is

$$
\left(1-\beta_{i(1, t)}\right)\left(1-\beta_{i(2, t)}\right)\left(m c_{i(1, t), t}-m c_{i(2, t), t}\right)
$$

Thus, if the investor has chosen a bargaining order with $m c_{i(1, t), t}>m c_{i(2, t), t}$, the investor can increase $r_{i(1, t), 1, t}^{*}$ by switching the first and second banks. The same applies to any consecutive pair of banks in the bargaining order. Hence the optimal bargaining order must be such that $m c_{i(j, t), t} \leq m c_{i(j+1, t), t}$ for all $j$. That is, the investor bargains with the banks in order from lowest to highest marginal cost of balance sheet for that day, just as in the baseline model with only two banks.

As above, let $i_{t}^{*}$ be the bank with the lowest value marginal cost $m c_{i t}$ on day $t$. The 
equilibrium interest rate on day $t$ is $r_{t}^{*}=r_{i_{t}^{*}, 1, t}^{*}$, and using $(23)$, we can express this rate as

$$
\begin{aligned}
& r_{t}^{*}=\left(1-\Pi_{i=1}^{N} \beta_{i}\right) \text { ioer }+\left(\Pi_{i=1}^{N} \beta_{i}\right) \text { repo }^{*} \\
& -m c_{i_{t}^{*}, t}\left(1-\beta_{i_{t}^{*}}\right)-\sum_{j=2}^{N} m c_{i(j, t), t}\left(1-\beta_{i(j, t)}\right) \Pi_{k=1}^{j-1} \beta_{i(k, t)} \\
& =\left(1-\beta_{i_{t}^{*}} \prod_{\substack{i=1 \\
i \neq i_{t}^{*}}}^{N} \beta_{i}\right) i o e r+\left(\beta_{i_{t}^{*}} \prod_{\substack{i=1 \\
i \neq i_{t}^{*}}}^{N} \beta_{i}\right) \operatorname{repo}^{*}-m c_{i_{t}^{*}, t}\left(1-\beta_{i_{t}^{*}}\right) \\
& -\beta_{i_{t}^{*}}\left(m c_{i(2, t), t}\left(1-\beta_{i(2, t)}\right)+\sum_{j=3}^{N} m c_{i(j, t), t}\left(1-\beta_{i(j, t)}\right) \Pi_{k=2}^{j-1} \beta_{i(k, t)}\right) \\
& =\left(1-\beta_{i_{t}^{*}} \beta_{-i_{t}^{*}}\right) \text { ioer }+\left(\beta_{i_{t}^{*}} \beta_{-i_{t}^{*}}\right) \text { repo }^{*}-m c_{i_{t}^{*}, t}\left(1-\beta_{i_{t}^{*}}\right) \\
& -\beta_{i_{t}^{*}}\left(1-\beta_{-i_{t}^{*}}\right) m c_{-i_{t}^{*}}
\end{aligned}
$$

where

$$
\beta_{-i_{t}^{*}}=\prod_{\substack{i=1 \\ i \neq i_{t}^{*}}}^{N} \beta_{i}
$$

and

$$
m c_{-i_{t}^{*}}=\left(1-\beta_{-i_{t}^{*}}\right)^{-1}\left(m c_{i(2, t), t}\left(1-\beta_{i(2, t)}\right)+\sum_{j=3}^{N} m c_{i(j, t), t}\left(1-\beta_{i(j, t)}\right) \Pi_{k=2}^{j-1} \beta_{i(k, t)}\right) .
$$

Equation (25) is identical to (14) in the two-bank model but with $\beta_{d}$ replaced by $\beta_{-i_{t}^{*}}$ and $m c_{d t}$ replaced by $m c_{-i_{t}^{*}}$. Thus, the model with two banks can stand in for a model with $N>2$ banks so long as we define the bargaining weights and balance sheet costs appropriately.

As banks are added to the model, $\beta_{-i_{t}^{*}}$ decreases. Thus, when more banks are competing, the bargaining power of the representative single bank of a type is lower. Competition reduces bargaining power because it gives the investor more alternative options. In this sense, the bargaining weights $\beta_{d}$ and $\beta_{f}$ in the two-bank model can be interpreted as indexing the amount of competition within the real-world group of banks of each type.

\section{Conclusion}

This paper uses a simple bargaining model to assess the influence of domestic and foreign banks' bargaining power, balance sheet costs, and repo rates on the fed funds rate. The model is able to explain the rise in the fed funds rate relative to the interest rate on 
excess reserves in 2018 and attributes this development to the rise in repo rates, not to any change in reserve scarcity.

\section{References}

Afonso, Gara, Roc Armenter, and Benjamin Lester. 2018. "A Model of the Federal Funds Market: Yesterday, Today, and Tomorrow." Staff Report No. 840, Federal Reserve Bank of New York.

Armenter, Roc, and Benjamin Lester. 2017. "Excess reserves and monetary policy implementation." Review of Economic Dynamics 23, 212-235.

Banegas, Ayelen, and Manjola Tase. 2016. "Reserve Balances, the Federal Funds Market and Arbitrage in the New Regulatory Framework." Finance and Economics Discussion Series 2016-079, Board of Governors of the Federal Reserve System.

Bech, Morten L., and Elizabeth Klee. 2011. "The mechanics of a graceful exit: Interest on reserves and segmentation in the federal funds market." Journal of Monetary Economics 58, 415-431.

Board of Governors of the Federal Reserve System. "Factors Affecting Reserve Balances." Statistical release H.4.1, April 26, 2018.

Federal Deposit Insurance Corporation. 2016. "Surcharges and assessments required to raise the reserve ratio of the DIF to 1.35 percent." Code of Federal Regulations, title 12, section 327.11 .

Federal Deposit Insurance Corporation. 2018. "Recent Changes to Assessments." Accessed May 16, 2018, at https://www.fdic.gov/deposit/insurance/assessments/ changesassessments.html.

Federal Financial Institutions Examination Council. 2017. Uniform Bank Performance Reports for December 31, 2017. Downloaded May 16, 2018, from https://cdr.ffiec.gov/ public/. 
Federal Reserve Bank of New York. 2017. "Reverse Repo Data by Counterparty Type since 9/23/2013 (Data updated as of 12/31/2017)." Downloaded May 16, 2018, from https://www.newyorkfed.org/medialibrary/media/omo/file/Reverse\%20Repo\% 20Data\%20by\%20Counterparty\%20Type.xlsx.

Ihrig, Jane E., Ellen E. Meade, and Gretchen C. Weinbach. 2015. "Rewriting Monetary Policy 101: What?s the Fed?s Preferred Post-Crisis Approach to Raising Interest Rates?" Journal of Economic Perspectives 29(4), 177-198.

Keating, Thomas, and Marco Macchiavelli. 2017. "Interest on Reserves and Arbitrage in Post-Crisis Money Markets." Finance and Economics Discussion Series 2017-124, Board of Governors of the Federal Reserve System.

Nash, John F., Jr. 1950. "The Bargaining Problem." Econometrica 18(2), 155-162. 